\title{
Juventude e consumo de drogas: oficinas de instrumentalização de trabalhadores de instituições sociais,
na perspectiva da saúde coletiva
}

\section{Introdução}

O objeto deste estudo é a oficina de instrumentalização de trabalhadores de instituições sociais que têm os jovens como população-alvo, para a compreensão do consumo contemporâneo de drogas - na perspectiva da Saúde Coletiva - no território de abrangência de uma Unidade Básica de Saúde (UBS), no município de São Paulo.

Resultado de pesquisa anterior na área de abrangência dessa UBS (Campos, 2004) mostrou a preocupação dos moradores do bairro a respeito do envolvimento dos jovens com drogas, lícitas e ilícitas, tanto no que se refere ao consumo quanto ao tráfico. Atribuído à falta de perspectiva de inserção no mercado de trabalho e à impossibilidade de acessar o consumo de produtos que os alça à condição de algum pertencimento, tal envolvimento é característico dos tecidos sociais das periferias das grandes cidades.

Mediante tais resultados e na perspectiva de fortalecer a cooperação interinstitucional - entre o Departamento de Enfermagem em Saúde Coletiva da Escola de Enfermagem da Universidade de São Paulo (EEUSP) e a UBS Vila Dalva foi feita a proposta de um ciclo de oficinas educativas.

Historicamente, os jovens dificilmente procuram a UBS para vocalizar suas necessidades de saúde, e, quando o fazem, é para resolver problemas pontuais vacinação, algumas doenças, ou para buscar recursos tradicionalmente oferecidos, como testes de gravidez e métodos contraceptivos (preservativos e pílulas anticoncepcionais).

Embora, a partir de 1990, o Sistema Único de Saúde (SUS) e o Estatuto da Criança e do Adolescente (ECA) coloquem o adolescente como sujeito do direito à saúde, as políticas de saúde que orientam as práticas em UBS ainda são escassas e restritivas, e deixam de lado um conjunto expressivo de jovens que já atingiram a maioridade (Amarante, 2007).

Esse quadro não é diferente no município de São Paulo. Dentre as poucas diretrizes disponíveis na Secretaria Municipal de Saúde, observa-se, em documento norteador, uma focalização da atenção à saúde do jovem em vulnerabilidades dificuldades nas relações familiares, uso de drogas lícitas e/ou ilícitas, início da vida sexual, DST/AIDS, gravidez, aborto e suas consequências, exclusão social, risco de suicídio, acidentes de trânsito, violência doméstica e sexual (Amarante, 2007).

${ }^{1}$ Enfermeira. Departamento de Enfermagem em Saúde Coletiva, Universidade de São Paulo. Av. Dr. Enéas de Carvalho Aguiar, 419, sala $233,2^{\circ}$ andar. Cerqueira César, São Paulo, SP, Brasil. 05.403-000 cassiaso@usp.br

${ }^{2,3}$ Enfermeira. Escola de Enfermagem, Universidade de São Paulo.

${ }^{4}$ Enfermeira. Centro de Capacitação Veleiros. 
Porém, pressupõe-se que a abordagem dessas vulnerabilidades seja complexa, o que requer do trabalhador uma formação mais ampla, que vá além do estabelecimento de fluxogramas de acolhimento e/ou de desenvolvimento de programas ou práticas centradas na atenção aos problemas pontuais, historicamente reconhecidos como necessidades nas UBS.

No entanto, os trabalhadores da atenção básica à saúde que, na maioria das vezes, por iniciativa própria, desenvolvem atividades voltadas para os jovens, ressentem-se da falta de capacitação para o trabalho (Amarante, 2007), ainda mais quando o tema em questão é o consumo de drogas.

Estudo desenvolvido por Canoletti e Soares (2005) atesta que os projetos de prevenção ao consumo prejudicial de drogas no Brasil - que, até a década de 1980, eram pautados em uma política ocasional e descontínua - a partir da década de 1990, começam a sofrer modificações, impulsionadas pelas políticas relacionadas à prevenção da Aids. Observa-se, então, uma crítica em relação às abordagens aterrorizantes que compunham o arsenal da abordagem da guerra às drogas, trazida dos Estados Unidos, e uma preocupação com a educação dos jovens. Embora não seja tão recente, trata-se de um movimento ainda incipiente e em transição, cujo foco se desloca da droga para o indivíduo que consome a droga e, em alguma medida, também para o contexto social; no entanto, sem discutir as raízes estruturais do envolvimento dos indivíduos com a droga.

Assim, parte-se do pressuposto de que os trabalhadores de instituições sociais, participantes das oficinas - ao menos em sua maioria - sentem-se despreparados para abordar essa temática com os jovens, e quando o fazem, tendem a apoiar-se em uma perspectiva que coloca, sobre o jovem, a responsabilidade pelo envolvimento com as drogas e pelos prejuízos que podem daí advir, atribuindoIhe, também, a responsabilidade pela mudança.

Nessa direção, as oficinas propostas partiram do quadro teórico formado pelos conceitos de juventude e de consumo de drogas na perspectiva da Saúde Coletiva, e da educação como instrumentalizadora da práxis criativa.

Juventude foi compreendida para além de uma classificação etária, e a adolescência como a primeira etapa dessa juventude, com o cuidado de não tomá-la como grupo identitário - "[...] os adolescentes se diferenciam pela sua história de vida de acordo com sua inserção sócio-econômica e seu desenvolvimento psicológico particular num contexto histórico e cultural dado" (Soares, 1997, p.37). Nessa direção, Abramo (2005) alerta para a ocorrência de juventudes, salientando as diferenças e desigualdades sociais que atravessam essa condição e estão na raiz das diferentes vivências dessa fase da vida nos diferentes grupos sociais.

No que diz respeito às substâncias psicoativas (drogas lícitas e ilícitas), a abordagem feita pela área da saúde toma, como foco, o âmbito das características da substância (farmacologia) ou o sujeito dependente (psiquiatria). Raramente são discutidas e abordadas as causas que estão nas raízes do consumo, da produção e da distribuição das drogas (Soares, Campos, 2004).

Sob a ótica da Saúde Coletiva, o consumo de drogas é definido histórica, social e culturalmente. A partir da instauração do modo de produção capitalista, a droga passou a ser uma mercadoria, portanto passou a ser produzida para responder a uma das finalidades primordiais desse modo de produção - a geração de lucro (Soares, 1997).

Logo, para analisar o consumo contemporâneo de drogas - uma mercadoria - pela perspectiva da Saúde Coletiva, é imprescindível tomar, como ponto de partida, as consequências do modo de produção capitalista, tanto no consumo de drogas, como também na sua produção e distribuição.

O modo de produção capitalista na contemporaneidade - reorganizado pela estratégia do neoliberalismo - promove valores ligados ao desenvolvimento de competências individuais, para o alcance de posições de sucesso e fama, que geram a competição e o desenvolvimento de projetos individuais. Aos indivíduos que não alcançam essa meta e que têm tido dificuldade de acesso aos bens socialmente produzidos - materiais e imateriais - é atribuído o peso da culpa individual, desarticulado de análise da conjuntura estrutural.

Para o pensamento neoliberal, os indivíduos são portadores de competências para buscar o caminho do sucesso. Logo, cabe a esses a concretização das aspirações e dos projetos idealizados, bem como a culpa por não atingirem o sucesso requerido; cabe aos indivíduos a culpa pelo fracasso e, também, a busca de saídas individuais para os problemas. 
É inegável que existe uma complexa relação entre os indivíduos e as drogas no mundo contemporâneo, na qual a droga é compreendida como uma resposta adaptativa, tanto para os indivíduos que se envolvem no tráfico - que tem sido tomado como mercado de trabalho, num contexto em que a vida contemporânea é dirigida pela busca de inserção e acesso ao mercado de trabalho e consumo - quanto para o consumidor da droga, que busca, na mercadoria droga, uma resposta aos desgastes, à necessidade de prazer rápido e de alívio para suas angústias (Soares, 1997).

Procurando compreender a ideologia dominante sobre o usuário de drogas e amparando-se em diversos autores da sociologia e antropologia, Soares (1997) conclui que o usuário de drogas ilícitas é julgado moralmente por infringir as regras sociais como um ser inferior, um criminoso, ou, no melhor dos casos, como um doente. Tal compreensão estigmatiza o usuário impondo-lhe, para além do preconceito, a marginalização e, muitas vezes, para os mais pobres, um último empurrão para a exclusão social.

Assim, postula-se que os projetos de prevenção tomem essa compreensão do consumo de drogas fundamentada nos conceitos da Saúde Coletiva, que considera que o envolvimento com essas substâncias tem, nas suas raízes, determinantes que ultrapassam características atreladas à fase da vida ou às características individuais.

No que diz respeito a projetos de prevenção tomando como tema as drogas, uma síntese de Soares (1997) mostra que vários especialistas na área discutem a importância de se fornecer informação correta sobre as substâncias psicoativas, uma vez que a informação subsidia a reflexão crítica acerca do tema, possibilitando um diálogo aberto e confiável entre os sujeitos da prevenção. A informação eficiente é aquela que possibilita uma análise em relação às opções possíveis, quais sejam: o uso racional e responsável de drogas ou os benefícios da abstinência. Carlini-Cotrim (1992) pondera que não se deveria interferir no direito que o cidadão tem sobre o seu corpo, e que o uso de drogas não necessariamente interfere negativamente sobre a sociedade. Sendo assim, a competência do Estado sobre o consumo de drogas deveria circunscrever-se às ações que interferem diretamente na sociedade, isto é, aquelas que incidem sobre os danos relacionados à saúde e, sobretudo, à violência. Portanto, seria sobre esses danos, e não sobre o arbítrio dos cidadãos sobre si mesmos, que deveriam recair as políticas de prevenção ao uso de drogas, o que configuraria programas realistas, eficientes, eticamente corretos e providos de credibilidade.

Para Acserald (2005), a abordagem educativa dialógica é a que permite a construção educativa coletiva, na qual os sujeitos envolvidos no processo assumem compromissos políticos com a democracia e com a expansão da liberdade do sujeito.

A educação, segundo Paro (2001), pode ser definida como apropriação do saber historicamente produzido, sendo o recurso que as sociedades têm para que a cultura seja passada de uma geração para outra.

Nessa perspectiva, é possível a conformação de uma educação crítica, que, articulando-se com as forças emergentes da sociedade, busque converter-se em instrumento a serviço da instauração de uma sociedade igualitária. Ainda que determinado, não deixa de influenciar o elemento determinante. Ainda que secundário, nem por isso deixa de ser instrumento importante e, por vezes, decisivo no processo de transformação da sociedade (Saviani, 2003).

O processo educativo é um processo de trabalho que somente se desencadeia em função da presença de sujeitos - educadores e educandos - que coproduzem o processo, de um objeto - estado de conhecimento - a ser transformado por meio de métodos e técnicas (Freire, 2002). Enfatiza-se ainda, segundo Freire (1997), a diretriz de que ensinar não é transferir conhecimento, mas criar a possibilidade para a sua própria produção, com base na experiência dos educandos.

O objeto do processo educativo é a práxis, que se refere à ação do homem que transforma a natureza fundamentada em uma teoria que guia a ação. Uma atividade propriamente humana é composta de ações que se dirigem para um objeto com a finalidade de transformá-lo, buscando um resultado o mais próximo possível daquilo que foi idealizado (Pereira, 2005). A forma como a consciência está presente na atividade prática do sujeito configura diferentes níveis de práxis, que então pode ser criativa ou reiterativa (Vázquez, 1977).

Tomando-se, então, essa compreensão teórica a respeito do envolvimento de jovens com as drogas 
na contemporaneidade, bem como a respeito do que sejam processos educativos na perspectiva emancipatória, oficina foi definida, neste trabalho, como: um instrumento que proporciona um espaço de reflexão sobre a práxis, em que os sujeitos - agentes e coprodutores do processo educativo participam com a finalidade de transformar a práxis reiterativa em práxis criativa.

O objetivo deste trabalho foi relatar e analisar uma experiência educativa, tendo a oficina como instrumento do processo educativo.

\section{Metodologia}

Partindo-se do quadro teórico exposto, este trabalho tomou a oficina como instrumento do processo de aprimoramento das práticas de trabalhadores de instituições sociais, focalizando aquelas voltadas aos jovens, na especificidade da compreensão do envolvimento desses jovens com as substâncias psicoativas (drogas lícitas e ilícitas) - seja no âmbito da distribuição (tráfico) ou do consumo -, por tratarse de instrumento potente para efetivar um processo de educação dialógica, muito apropriada na abordagem do tema em questão.

A expressão oficina é muito pouco utilizada na produção científica da área da educação em saúde, destacando-se o trabalho pioneiro de Chiesa e Westphal (1995).

Os objetivos das oficinas foram: sensibilizar os trabalhadores das instituições sociais para o tema das drogas, e aprimorar o conhecimento desses trabalhadores a respeito da distribuição e do consumo contemporâneo das drogas psicoativas, especialmente entre os jovens, na perspectiva da Saúde Coletiva.

Este trabalho utilizou uma metodologia inspirada em Freire $(2002,1997)$, buscando, também, levar em conta a proposta metodológica de Saviani (2003), que se expressa nas seguintes etapas: 1. prática social: professor e aluno, agentes sociais, encontram-se em níveis diferentes de compreensão (conhecimento e experiência) da prática social - o professor tem uma compreensão denominada de síntese precária e a compreensão do aluno é de caráter sincrético; 2 . problematização: identificação dos principais problemas colocados pela prática social; 3. instrumentalização: apropriação, pelas camadas populares, das ferramentas culturais necessárias à luta social que travam diariamente para se libertarem das condições de exploração em que vivem; 4. catarse: efetiva incorporação dos instrumentos culturais, transformados, agora, em elementos ativos de transformação social. O momento catártico é o ponto culminante do processo educativo - a passagem da síncrese (a visão caótica do todo) à síntese (uma rica totalidade de determinações e de relações numerosas), pela mediação da análise (as abstrações e determinações mais simples); 5 . ponto de chegada: percepção da alteração qualitativa da prática social do início para o final do processo.

A pedagogia histórico-crítica proposta por Saviani (2003) estimula a iniciativa e a criatividade dos participantes - sem perder de vista o conhecimento historicamente produzido. Da mesma forma, Freire propôs a educação dialógica como forma de resgatar o conhecimento e a experiência advindos na prática social.

Essa perspectiva emancipatória de educação guarda coerência com a necessidade de se buscar um fundamento dialético - que articula teoria e prática - para analisar a realidade social e de saúde dos jovens com os quais trabalham; e, ao mesmo tempo, propor ações solidárias e coletivas, numa perspectiva de superação daquelas pautadas preponderantemente em conhecimentos de senso comum.

Para a realização das oficinas, contatou-se cada uma das dez instituições sociais da Vila Dalva, bairro da região oeste do município de São Paulo, que trabalhavam com jovens, para saber quais já haviam abordado a temática das drogas em suas palestras, grupos ou reuniões; e constatou-se que não havia trabalho específico em nenhuma delas. Foi feito um convite para que dois trabalhadores de cada instituição participassem do processo.

Foram conduzidas cinco oficinas na UBS V. Dalva, para 28 participantes, divididos em duas turmas, em dias e horários distintos, de acordo com a disponibilidade. Participaram das oficinas: professoras da escola de $1^{\circ}$ e $2^{\circ}$ graus, a coordenadora de uma das creches, trabalhadores das duas ONGs (Instituto Stefanini e Espaço dos Sonhos), agentes comunitários de saúde e enfermeiras da UBS, trabalhadora do 
Centro de Convivência e Cooperativa da região, e trabalhadora da Associação Criança Brasil Núcleo Socioeducacional.

Os temas das oficinas foram definidos a cada encontro, com base no desenvolvimento da discussão, o que pode ser visualizado no Quadro 1.

Todas as discussões foram gravadas com a autorização prévia do grupo. O conteúdo das fitas foi transcrito e os depoimentos foram analisados pelo método da análise temática (Bardin, 2000).

\section{Resultados}

O processo educativo, tomado nessa perspectiva emancipatória, não permite uma visualização das etapas didaticamente descritas numa sequência gradual e linear de apropriação e complexificação do conhecimento.

Assim, numa mesma oficina, foram observadas várias das etapas propostas por Saviani. Por isso, a análise apresentada tomará, como referência, o processo como um todo.

As etapas do processo educativo permitiram que os participantes, ao trazerem suas experiências e conhecimentos provisórios para o espaço da oficina, contribuíssem para nortear as discussões posteriores, conforme o depoimento: “É isso porque partiu de nós aqui, vocês não trouxeram. Eu até falei com a professora, eu achei tão diferente do que tava pensando, pensei que fosse chegar aqui e tá tudo explicadinho aí" (P1).

O quadro 1 apresenta as temáticas eleitas pelo grupo de participantes.

Quadro 1. Distribuição dos temas, objetivos e estratégias das oficinas emancipatórias sobre juventude e consumo de drogas. São Paulo, UBS Vila Dalva, 2006.

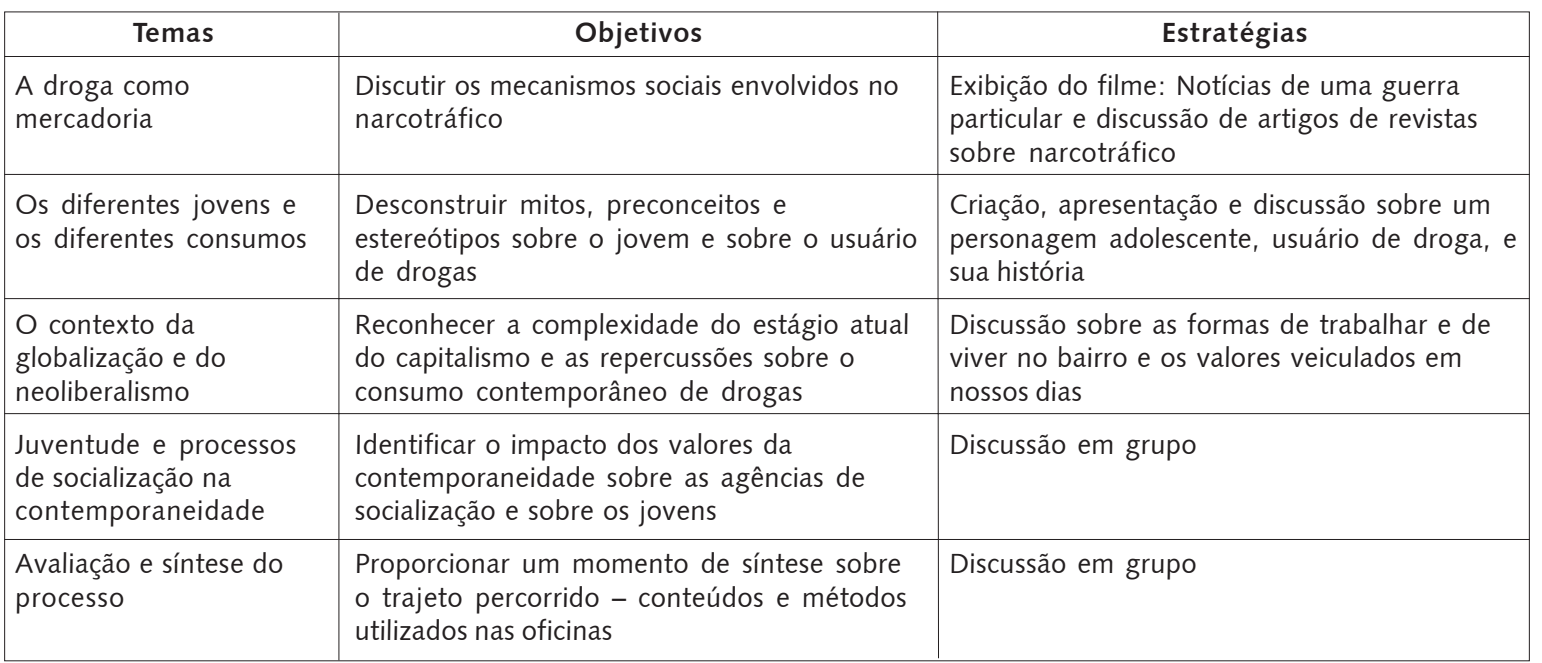

No primeiro encontro, foi solicitado que cada um dissesse por que veio participar da oficina, quais as expectativas, e que respondesse a pergunta: por que as pessoas usam drogas?

Inicialmente, identificou-se que os participantes associaram os motivos pelos quais as pessoas usam drogas com saberes do senso comum:

[...] São várias coisas, [...] depende da pessoa, cada uma vai ter um porquê [...] umas [pessoas] [...] é a própria necessidade do organismo, que já ta precisando da droga, outras é 
pela parte mental, que vai aliviar a dor que ela sente por algum problema, ou até pelo fato de ser aceito numa comunidade, [...] assim as pessoas se envolvem.

E eu acho que a causa [...] tem vários fatores. [...] A criançada [...] alguns não têm a orientação dos pais, mas o envolvimento também é por falta de diálogo [...], e tem fator cultural também e sociais também, [...] alguns é [...] fraqueza, [...] se sentem fraco e se envolvem, [...] é uma válvula de escape no caso. Tem vários fatores e ainda não entendi muito, queria entender porque [...] eu morro de medo de passar por isso. (P2)

No encontro seguinte, os participantes criaram e descreveram, em grupos, estórias de jovens usuários de drogas, que contivessem: idade, sexo, se estuda e/ou trabalha; atividades que compõem o seu dia a dia; características de sua personalidade; droga(s) que está usando e com que frequência; como começou o uso e quais eram suas motivações iniciais; relação com: a família, a escola, o trabalho, o grupo de amigos e outras pessoas com quem se relaciona; com que $(m)$ se identifica e do que gosta.

Em todos os grupos, o consumidor de drogas foi descrito de forma caricata, e sua vida inexoravelmente associada à decadência física e moral, tendo um fim sempre trágico, como sugerido no excerto abaixo.

Ela tem 14 anos, [...] estuda [...], não falta comida, não falta roupa, não falta o brinco [...], mas o que falta pra ela é o carinho [...] dos pais [...]. Eles moram na favela e pra ela ir pra escola ela passa no meio dos menino que ficam vendendo [drogas], [eles] mexem com ela, [...] ela até tem interesse por um que trabalha lá [...]. Ela começou a fumar pra ta na altura dele [e] [...] do grupo, ela vai mesmo pela cabeça dos outros. [...] Ela começou a passar lá, eles começam a conversar: você vende maconha? quanto custa? [...] Ele não vende pra ela no começo, ele dá [...] e ela [...] começou a se envolver. Acho que [...] ela tinha ele como um ídolo, tanto que ela mudou o jeito de ser dela para conquistar ele. [...] Ela [se envolveu] com bebidas e [...] em casa de prostituição [...], até mesmo os caras com quem ela sai, se prostitui, ela vai $[\ldots]$ com quem tem dinheiro [...], acho que adere a isso aí. (P3)

No terceiro encontro, após assistir ao filme que trata do tema do tráfico de drogas no Rio de Janeiro, na perspectiva da polícia, do traficante e do morador da favela que abriga o ponto do tráfico, os participantes fizeram comparações com os problemas do bairro, apontaram similaridades e diferenças de contexto de vida dos moradores e dos jovens do filme e os da Vila Dalva.

No encontro seguinte, foi lido e discutido em grupos o texto "Tráfico nada tem de revolucionário", de Marcelo Freixo, retirado da Folha de São Paulo de 26 de março de 2006, tendo como questão norteadora: qual a importância do modo de produção capitalista para o consumo de drogas (um produto de mercado)? Com a síntese feita pelas coordenadoras, o grupo estabeleceu relações entre o processo de produção, distribuição e consumo de drogas e as características de trabalho e vida dos moradores da Vila Dalva, especialmente as dos jovens.

As oficinas permitiram que os participantes relacionassem os problemas cotidianos (microcontextos) das instituições sociais representadas, com os aspectos da estrutura e dinâmica social do capitalismo (macrocontextos), como mostram os excertos abaixo:

A televisão passa tudo aquilo que você quer [ter] e às vezes você não tem, [mas] vai ser bombardeada. [...] Um jovem [...] da periferia mais ainda [...], todos usam tal tênis, todos usam tal camiseta, é a questão de inserção no grupo. Então aquele [grupo a] que eu quero pertencer, [se] as pessoas fumam, ai eu também quero pertencer. (P4)

Se [o jovem] acorda, vem pra rua, o que que tem? Não tem nada pra fazer, não tem nada, não tem uma estimulação pra você praticar um esporte, não tem eventos pra você ir. Então [...] [o jovem] vai tá tipo no deserto, não tem nada pra fazer, vai procurar droga mesmo. Ah! vou experimentar, é bom. A sensação deve ser boa mesmo, porque senão eles não usavam, 
né? Acho que é isso mesmo, sai de casa e não tem nada pra fazer, não tem onde ir, não tem parque, [...], não tem amigos, não tem trabalho. Principalmente trabalho [...]. (P5)

As oficinas também permitiram uma análise da realidade que interpreta o envolvimento com as drogas de forma menos preconceituosa e menos identificada com o senso comum, o que permite uma aproximação com os jovens e com usuários.

[...] Por que tem que acabar sempre assim tragicamente? [...] a pessoa pode parar de beber e continuar tomando um drink de vez em quando [...]. (P6)

O que é acabar mal, é a pessoa continuar usando droga? E acabar bem, é ela parar de usar? [...] A pessoa não pode ter uma vida boa, uma vida normal, viver dentro dos conformes usando de vez em quando? Tem quem tenha uma vida normal, trabalhando. (P7)

No começo a gente tava muito confuso, a gente não encontrava [...] quem é o culpado, é os pais que foram trabalhar e deixou lá na casa, é a escola que os professores não tão mais nem aí, [...] ou era ele mesmo. Mas agora [...] eu responderia [...] coitado do cara que caiu na droga [...] porque eu acho que ele não é culpado, a família também não é culpada e a escola também não tem culpa nenhuma, eu acho que eles tão caindo na droga hoje por conta dessa situação toda, [...] a falta de emprego, tudo isso [...]. A gente entendeu melhor [...] porque eles acabam sendo discriminados, por uma razão que não tem nem sentido de ser porque de um jeito ou de outro quem não usa drogas? [...] (P6)

Eu tinha o costume já de julgar, né? Agora a gente procura saber primeiro o que que fez a pessoa chegar a esse ponto, [...] a gente procura saber a história da pessoa. Por mais errado que a gente ache que é aquela atitude, a gente até [...] compreende o porquê de tá acontecendo aquilo, né?. (P8)

Os participantes superaram concepções e práticas ingênuas, não apenas por meio de mudanças discursivas por referência aos conteúdos tratados, mas também por intermédio de atitudes e ações no cotidiano, como expressa o excerto abaixo.

No encontro passado a gente aqui teve uma discussão aberta, de como dar uma resposta, dar uma saída [para o problema] [...]. Ontem eu entrei numa sala para dar aula [...] e aí conversava com os meninos sobre um projeto de vida. [...] deixei um espaço pra discussão, vocês vão me montar um projeto, escrever uma redação [sobre] o que vocês querem, [na vida] [...] como vocês vão conseguir e quais os valores [que] vocês precisam prá fazer essa atividade [...]. Aí todo mundo ficou parado [e] perguntou assim para mim: mas o que é valor? [...]. Aí [...] falei: tá perto da eleição, a gente tá falando [...] tanto dos políticos que são corruptos [...]. Ele é honesto? Não. A honestidade é um valor? [...] Aí [...] quando peguei o segundo colegial eu fiz diferente, [...] fui por um outro caminho. [...] Ao invés de pedir pra cada um, [pedi] prá que se juntassem em grupos pra refletir [...], aí saiu, aí saiu alguma coisa. [...] se ficar colocando que só o que eu ganhei, comprei, tem valor, é aonde eu até vou correr pras drogas, por que? Porque vai existir lá dentro um espaço que ninguém vai preencher, conhecimento nenhum vai preencher. (P9)

Ao final do processo, os trabalhadores das diferentes instituições sociais propuseram, como continuidade dessa etapa, a criação de espaços de discussão no trabalho e a elaboração de projetos intersetoriais de prevenção do consumo prejudicial de drogas, especialmente do setor saúde com o da educação. 
[A saída] é criar momentos assim, [...] agora eu aprendi a pensar, raciocinar [...]. A gente pode tá trazendo gente que tá perdido também ou que tão no escuro. Que a gente consiga abrir um pouco a cabeça, se esses quatro ou cinco abrir de mais dois já ta bom [...]. (P6)

E porque não juntar essas famílias com nós profissionais do posto de saúde, com os profissionais da escola e fazer uma coisa junto, que eu acho que tem tudo a ver. Nós estamos ali, tendo contato com as famílias, os professores têm contato com os alunos, é importante a presença dos pais, né? Eu acho que seria super legal, [...] é difícil, mas a partir do momento que eles começarem a ver que tá tendo resultado [...]. (P8)

Verificou-se que a oficina constitui-se como instrumento potente de transformação do objeto do processo educativo. A potencialidade desse método para acessar conhecimentos foi também demonstrada por Andrade, Barbosa e Soares (2004), ao desenvolverem e analisarem um conjunto de oficinas em que participaram pais e educadores de uma escola de educação infantil. Assim, a oficina tomada como instrumento do processo de aprimoramento de conceitos e práticas - efetiva espaços: de expressão dos diferentes pontos de vista e percepção dos participantes; de discussão de crenças e de valores; estimula a utilização de noções já aprendidas em situações novas (Moreno et al., 2005), e favorece, pela sistematização de processos de racionalização, a construção coletiva de conhecimentos como resultado da reflexão problematizadora da realidade social concreta dos participantes (Andrade, Barbosa, Soares, 2004; Moreira, Barreto, 2004).

Resultado semelhante foi descrito por Jeolás e Ferrari (2003), quando mostraram que os exercícios e os temas trabalhados estimularam questionamentos e permitiram que fossem evidenciados possíveis determinantes externos - classe social, gênero, idade - que impõem limites reais à autonomia pessoal; os autores afirmaram que esse processo de construção coletiva é condizente com uma espécie de ruptura da alienação do dia a dia.

Na mesma direção, Patrício (1994) descreveu a efetividade das oficinas, concluindo que o processo permite que conceitos ingênuos ou preconceituosos sejam superados, o que possibilita uma leitura crítica da realidade.

Moreira e Barreto (2004), analisando o processo de oficinas realizadas com moradores de zona rural, descreveram propostas, feitas pelos participantes, de intervenção para a melhoria das condições de vida dos moradores daquele território, além das possibilidades de superação e construção de conceitos.

No que concerne especificamente ao tema do consumo de drogas por jovens, destaca-se a experiência de uso de um jogo educativo do Rio de Janeiro, que mostra a potência de um momento de reflexão lúdica para discutir a realidade, afastando-se de uma perspectiva de transmissão de informações, definidas a priori e distanciadas da realidade dos sujeitos. Os adolescentes avaliam positivamente o uso do Jogo da Onda, esclarecem que o jogo facilita a abordagem de temas pouco discutidos entre os próprios adolescentes, e que, se pudessem jogar com a família, seria mais fácil discutir esses assuntos em casa (Rebello, Monteiro, Vargas, 2001).

\section{Conclusão}

Avalia-se que a oficina é um instrumento potente para que os sujeitos - agentes e coprodutores do processo educativo - participem com a finalidade de transformar a práxis reiterativa em práxis criativa.

Foi possível aquilatar a efetividade do processo conduzido pelas oficinas, aferindo-o com as etapas da metodologia proposta por Saviani (2003).

Pode-se afirmar que as oficinas se configuram como prática social; no processo descrito neste artigo os participantes, inicialmente, tinham diferentes compreensões a respeito do consumo e do consumidor de drogas, embora prevalecesse o senso comum identificado com idéias comumente difundidas pelas mídias, idéias essas diferentes dos saberes produzidos pelas experiências concretas do cotidiano desses trabalhadores. 
Embora essas oficinas não tenham sido decorrência de solicitação desses participantes, o tema foi caracterizado como preocupante por moradores do bairro, em pesquisa anterior (Campos, 2004). Dessa forma, a apresentação da proposta das oficinas motivou os trabalhadores das instituições sociais do bairro, que já, nesse momento, verbalizaram alguns problemas colocados pela prática social e o interesse em participar.

Com o decorrer das oficinas, pôde-se constatar, por meio dos excertos transcritos das falas dos participantes, o processo de instrumentalização ocorrido, uma vez que os participantes foram se apropriando de conceitos e foram se ampliando as possibilidades de análise crítica da situação em que se encontram os jovens na contemporaneidade - em especial, na realidade do cotidiano desses trabalhadores, denotando um desenvolvimento de sua consciência em relação à situação enfrentada, ainda que não se possa assegurar a passagem, segundo Saviani (2003), da síncrese (a visão caótica do todo) à síntese (uma rica totalidade de determinações e de relações numerosas), pela mediação da análise (as abstrações e determinações mais simples).

O conceito dos participantes a respeito do consumo de drogas evoluiu qualitativamente, mostrando que os saberes identificados com os do senso comum inicialmente trazidos pelos trabalhadores - a culpabilização individual e familiar - se complexificaram para uma compreensão das raízes do consumo prejudicial de drogas e para a proposição da superação de práticas reiterativas de reprodução da ideologia dominante. Desfizeram-se também mitos, preconceitos e estereótipos a respeito do usuário frágil, influenciável, desmotivado e excluído - bem como a respeito do poder e dos efeitos das drogas.

Assim, a alteração qualitativa da prática social - ponto de chegada desse percurso - se efetivará quando os participantes implementarem projetos de prevenção do consumo prejudicial de drogas numa perspectiva emancipatória com os jovens, viabilizando trabalhos solidários em direção ao fortalecimento dos grupos sociais, para o enfrentamento das condições de exploração em que vivem.

\section{Colaboradores}

Cássia Baldini Soares e Célia Maria Sivalli Campos redigiram a versão final do artigo, articulando os resultados das monografias de final de curso, por elas orientadas, das alunas de graduação de enfermagem Adriana de Souza Leite e Cristina Lourdes Leite de Sousa.

\section{Referências}

ABRAMO, H.W. Condição juvenil no Brasil contemporâneo. In: ABRAMO, H.W.; BRANCO, P.P.M. (Orgs.). Retratos da juventude brasileira: análises de uma pesquisa nacional. São Paulo: Fundação Perseu Abramo, 2005. p. 37-72.

ACSERALD, G. A educação para a autonomia: construindo um discurso democrático sobre as drogas. In (Org.). Avessos do prazer: drogas, Aids e direitos humanos. 2.ed. Rio de Janeiro: Editora Fiocruz, 2005. p.183-212.

AMARANTE, A.G.M. Juventude no SUS: as práticas de atenção à saúde no Butantã. 2007. Dissertação (Mestrado) - Escola de Enfermagem, Universidade de São Paulo, São Paulo. Disponível em: <http://www.teses.usp.br>. Acesso em: 25 jun. 2007.

ANDRADE, S.C.; BARBOSA, R.C.; SOARES, C.B. Oficinas de discussão: uma proposta educativa em saúde como instrumento para a intersetorialidade. In: Comissão de Graduação da Escola de Enfermagem da USP. (Org.). VII Mostra de Monografias de Conclusão de Curso da EEUSP/2003. São Paulo: EEUSP, 2004. p.75-7. 
BARDIN, L. Análise de conteúdo. Lisboa: Edições 70, 2000.

CAMPOS, C.M.S. Necessidades de saúde pela voz da sociedade civil (os moradores) e do Estado (os trabalhadores de saúde). 2004. Tese (Doutorado) - Escolas de Enfermagem de São Paulo e Ribeirão Preto, Universidade de São Paulo, São Paulo. Disponível em: <http://www.teses.usp.br>. Acesso em: 8 jun. 2007.

CANOLETTI, B.; SOARES, C.B. Programas de prevenção ao consumo de drogas no Brasil: uma análise da produção científica de 1.991 a 2001. Interface - Comunic., Saude, Educ., v.9, n.16, p.115-29, 2005.

CARLINI-COTRIM, B.H. A escola e as drogas: realidade brasileira e contexto internacional. 1992. Tese (Doutorado) - Departamento de Psicologia Social, Pontifícia Universidade Católica, São Paulo. 1992.

CHIESA, A.M.; WESTPHAL, M. A sistematização de oficinas educativas problematizadoras no contexto dos serviços públicos de saúde. Saude Debate, n.46, p.19-22, 1995.

FREIRE, P. Pedagogia do oprimido. Rio de Janeiro: Paz e Terra, 2002.

Pedagogia da autonomia: saberes necessários à pratica educativa. Rio de Janeiro: Paz e Terra, 1997.

JEOLÁS, L.S.; FERRARI, R.A.P. Oficinas de prevenção em um serviço de saúde para adolescentes: espaço de reflexão e de conhecimento compartilhado. Cienc. Saude Colet., v.8, n.2, p.611-20, 2003

MOREIRA, L.M.C.; BARRETO, O. Saber é poder: relato de uma experiência de educação popular na busca da melhoria da qualidade de vida. Divulg. Saude Debate, n.31, p.4452, 2004.

MORENO, L.R. et al. Jornal Vivo: relato de uma experiência de ensino-aprendizagem na área da saúde. Interface - Comunic., Saude, Educ., v.9, n.16, p.195-204, 2005.

PARO, V.H. Escritos sobre educação. São Paulo: Xamã, 2001.

PATRÍCIO, Z.M. Nem talco nem diamante: a riqueza de um processo de ensinoaprendizagem participante na área da sexualidade-adolescência. Texto Contexto Enferm., v.3, n.2, p.93-109, 1994.

PEREIRA, E.G. A participação da enfermagem no trabalho educativo em Saúde Coletiva: um estudo dos relatos de experiência produzidos por enfermeiros brasileiros no período 1988-2003. 2005. Dissertação (Mestrado) - Escola de Enfermagem, Universidade de São Paulo, São Paulo. Disponível em: <http://www.teses.usp.br>. Acesso em: 8 jun. 2007.

REBELLO, S.; MONTEIRO, S.; VARGAS, E.P. A visão de escolares sobre drogas no uso de um jogo educativo. Interface - Comunic., Saude, Educ., v.5, n.8, p.75-88, 2001.

SAVIANI, D. Escola e democracia: teorias da educação, curvatura da vara, onze teses sobre a educação política. 36.ed. Campinas: Autores Associados, 2003. v.5.

SOARES, C.B. Adolescentes drogas e AIDS: avaliando a prevenção e levantando necessidades. 1997. Tese (Doutorado) - Faculdade de Educação, Universidade de São Paulo, São Paulo. Disponível em: <http://www.teses.usp.br>. Acesso em: 2 jun. 2007.

SOARES, C.B.; CAMPOS, C.M.S. A responsabilidade da universidade pública no ensino da prevenção do uso prejudicial de drogas. Mundo Saude, v.28, n.1, p.110-5, 2004.

VÁZQUEZ, A.S. Filosofia da práxis. Rio de Janeiro: Paz e Terra, 1977. 
O objeto deste estudo é a oficina de instrumentalização de trabalhadores de instituições sociais que trabalham com jovens, para compreender o consumo contemporâneo de drogas. Partiu-se do pressuposto de que a abordagem da temática na perspectiva da Saúde Coletiva, ou seja, a partir da compreensão estrutural da produção, distribuição e consumo contemporâneo de drogas, poderia aperfeiçoar o trabalho nessas instituições. O objetivo foi verificar a efetividade da oficina como instrumento do processo educativo. A metodologia consistiu na realização sistemática de oficinas com base no arcabouço teórico-metodológico da teoria histórico-crítica. A participação evoluiu qualitativamente, mostrando que os saberes identificados com os do senso comum inicialmente trazidos pelos trabalhadores evoluíram para uma compreensão das raízes do consumo prejudicial de drogas e para a superação de práticas reiterativas que retroalimentam mitos, preconceitos e estereótipos a respeito do usuário, bem como a respeito do poder e dos efeitos das drogas.

Palavras-chave: Juventude. Consumo de drogas. Educação. Saúde coletiva.

Young people and drug consumption: workshops to provide tools
for workers in social institutions, from a collective health perspective

The objective of this study was, through workshops, to provide tools for workers in social institutions who work with young people, so that they could understand present-day drug consumption. It started from the presupposition that approaching this topic from a collective health perspective, i.e. from understanding the structure of the production, distribution and consumption of drugs today, the work of these institutions might be improved. The aim was to investigate the effectiveness of workshops as tools in the educational process. The methodology consisted of systematically conducting workshops within a theoretical-methodological framework of historical-critical theory. The workers' participation evolved qualitatively, thereby showing that the knowledge identified, along with the common sense initially brought in, evolved into comprehension of the roots of harmful drug consumption and into surmounting reiterative practices that fed back into myths, prejudice and stereotypes regarding users, as well as gaining respect for the power and effects of drugs.

Key words: Young people. Drug consumption. Education. Collective health.

Juventud y consumo de drogas: talleres de instrumentalización de trabajadores de instituciones sociales en la perspectiva de la salud colectiva

El objeto de este estudio es el taller de instrumentalización de trabajadores de instituciones sociales que trabajan con jóvenes, para comprender el consumo contemporáneo de drogas. Se parte del presupuesto de que la aproximación de la temática en la perspectiva de la Salud Colectiva, o sea, a partir de la comprensión estructural de la producción, distribución y consumo contemporáneo de drogas, podría perfeccionar el trabajo en tales instituciones. El propósito ha sido verificar la efectividad del taller como instrumento del proceso educativo. La metodología consiste en la realización sistemática de talleres a partir de la estructura teórico-metodológica de la teoría histórico-crítica. La participación evolucionó cualitativamente, mostrando que los saberes identificados con los del sentido común inicialmente traidos por los trabajadores evolucionaron para una comprensión de las raíces del consumo perjudicial de drogas y para la superación de prácticas reiterativas que retro-alimentan mitos, preconceptos y estereotipos respecto al usuario, así como respecto al poder y a los efectos de las drogas.

Palabras clave: Juventud. Consumo de drogas. Educación. Salud Colectiva. 